\title{
A pilot evaluation of Swasthya Pahal program using SMAART informatics framework to support NCD self-management
}

\author{
Ashish Joshi ${ }^{1}$, Mahima Kaur ${ }^{2}$, Srishti Arora ${ }^{2}$, Ashruti Bhatt ${ }^{2}$, Priya Sharma ${ }^{2}$, Harpreet Kaur ${ }^{2}$, \\ Kanishk Kumar ${ }^{2}$, Mohit Arora $^{2}$, Bhavya Malhotra ${ }^{2}$, Ajay Anshuman ${ }^{3}$ \\ ${ }^{1}$ CUNY Graduate School of Public Health and Health Policy, New York, NY, USA; ${ }^{2}$ Foundation of Healthcare Technologies Society, New Delhi, \\ India; ${ }^{3}$ Uttarakhand State Police, Uttarakhand, India \\ Contributions: (I) Conception and design: A Joshi; (II) Administrative support: A Joshi; (III) Provision of study materials or patients: A Anshuman; (IV) \\ Collection and assembly of data: M Kaur, S Arora, A Bhatt, P Sharma, H Kaur, K Kumar, M Arora, B Malhotra; (V) Data analysis and interpretation: \\ A Bhatt; (VI) Manuscript writing: All authors; (VII) Final approval of manuscript: All authors. \\ Correspondence to: Ashish Joshi, PhD, MBBS, MPH. Senior Associate Dean Academic and Student Affairs, CUNY Graduate School of Public Health \\ and Health Policy, City University of New York, NY, USA. Email: ashish.joshi@sph.cuny.edu.
}

Background: Empirical research acknowledges the capability of mHealth and eHealth interventions for ensuring high-quality and tailored healthcare to individuals. People living with various health conditions get access to a wide range of healthcare services through digital interventions. The aim of the study is to examine the usefulness of Swasthya Pahal, a community-based Health for all program, aimed to enhance screening and self-management of diabetes, hypertension, and obesity among police personnel.

Methods: A convenient sample of 64 individuals aged 18 years and above present at the Police Sanchar Training Centre, Dehradun, Uttarakhand were enrolled over 2 days in January 2020. The Swasthya Pahal pilot program was approved by the Uttarakhand State Police authorities. Individuals' health data was recorded using an interactive, bi-lingual, touch screen, computer-based program. Subjective data was collected and self-reported information was gathered about (I) socio-demographics, (II) health behaviors, (III) clinical status, and (IV) Knowledge, Attitudes, and Practices (KAP). Objective data assessments included measurements such as weight, blood pressure, and blood sugar levels using a series of physiological sensors. Additional information gathered at 1 month follow up included modifications that individuals made in their self-management of diabetes and hypertension, diet, physical activity, alcohol consumption, and smoking. Information was gathered related to individuals' interest in receiving SMS based health messages.

Results: The average age of study participants was 37 ( $\mathrm{SD}=8$ ) years, $88 \%$ were males, and $42 \%$ had graduate education. Hypertension (31\%) was found to be the most common family history. Thirty-six percent of individuals were presently smokers or consumed alcohol. Sixty-two percent of them self-reported doing some form of exercise. Walking, jogging and yoga were the most common exercise types. Eightyseven percent of them were not receiving any treatment to self-manage hypertension. Based on the JNC 8 criteria, $37 \%$ of the individuals were hypertensive. Fifty of the 64 individuals expressed interest to receive SMS message, 64\% of them expressed keenness to receive weekly SMS messages. Messages related to diet, physical activity, sleep, and smoking and alcohol consumption were perceived as important.

Conclusions: The Swasthya Pahal program using the SMAART informatics framework is a useful tool to enhance screening and self-management of non-communicable diseases (NCDs) among police personnel.

Keywords: Non-communicable diseases (NCDs); informatics; self-management; population health

Received: 02 April 2020; Accepted: 17 January 2021; Published: 20 October 2021.

doi: $10.21037 /$ mhealth-20-110

View this article at: http://dx.doi.org/10.21037/mhealth-20-110

(c) mHealth. All rights reserved. 


\section{Introduction}

The World Health Organization (WHO) describes noncommunicable diseases (NCDs) as chronic ailments of the long term as a consequence of an interplay of genetic, behavioral, physiological, and environmental factors (1). The Global Action Plan for the Prevention and Control of NonCommunicable Diseases was signed by the WHO member states to cease the rise of diabetes by 2025 and decrease the prevalence of hypertension by $25 \%$ between 2010 and 2025 (2). A target has been set by the United Nations (UN) member states as a part of Sustainable Development Goal 3 to reduce premature deaths from NCDs by one-third by $2030(3)$.

India faces a huge burden of NCDs and faces a serious challenge in achieving the SDG goal 3 Good Health and Well-Being. In recent years, India has undergone demographic and epidemiological shifts, leading to a transition from infectious diseases to NCDs (4). Consumption of tobacco and alcohol, sedentary lifestyle, overweight and obesity, increased intake of fat and sodium intake, and low intake of fruits and vegetables, are the various behavioral and biological risk factors of NCDs (5). Along with the behavioral and biological risk factors, other factors such as individuals' job profile and the workplace environment play a role in the development of NCDs (6).

Police personnel is among the special occupational groups who are highly affected by the risk factors of NCDs. They have to serve day-and-night for providing safety to the citizens. Susceptibility of police personnel to various NCD's risk factors increases due to poor lifestyle, erratic eating habits, disturbed sleep, work-related stress, transferable jobs, and shifting duties. Prior studies have shown a high burden of hypertension and risk factors among law enforcement officers. Also, prior studies have shown poor awareness and lifestyle, and treatment-seeking behavior among the enforcement personnel (7). Study participants had poor knowledge and sub-standard health behavior to NCDs and its risk factors. Inadequate awareness and poor practices impede primary and secondary prevention strategies for averting NCDs (8). Police work is one of the most stressful occupations in the world (9).

The WHO acknowledges the capability of digital health interventions for ensuring high-quality care to people (10). Digital innovations allow individuals exclusive approach to information and computing power. Internet's ability to facilitate faster and more efficient data storage and sharing has accelerated the diffusion of innovation for sustainable development (11).

Technological interventions have been tailored for delivering a wide spectrum of healthcare services for individuals living with various diseases (4). Information and Communication Technologies (ICTs) have the potential to offer affordable and high-quality services (12). Health information programs can be customized according to the needs of the community by incorporating high interactivity and usability levels (13). The optimal way to execute decisions about the implementation of technology should integrate variable considerations including cost per unit, how to encourage uptake, whether technology can work in a particular setting (14).

The primary objective of this study is to examine the usefulness of Swasthya Pahal, a community-based Health for all program aimed to enhance self-management of NCDs including diabetes, hypertension, and obesity among police personnel in an Indian setting. The program is implemented using an interactive, touch screen, multilingual, portable health information kiosk designed and developed using Population Health Informatics (PopHI) framework called SMAART (Sustainable Multisector Accessible Affordable Reimbursable Tailored) which was previously published. To the best of our information, this is the first study to assess the use of a PopHI platform to address the burden of NCD among police personnel. We present the following article following the MDAR reporting checklist (available at http://dx.doi.org/10.21037/ mhealth-20-110).

\section{SMAART informatics framework}

The effectiveness of healthcare is a multidimensional concept which needs amalgamation of social determinants of health with policy to reduce health inequities. The multi-layered analysis needs to be in favor of the end user's method of processing knowledge. There is a growing need for approaches and tools to support the build-up the knowledge gaps (15).

SMAART informatics framework facilitates the integration of social factors of health data with clinical data to alleviate population health outcomes across individuals living in diverse geographical settings (16). The framework is operationalized as an interactive, standalone, and Internet-enabled platform that facilitates (I) transmission of data and information regarding the health status of the consumer, (II) interprets data and information in an evidence-based manner (III) address the specific 


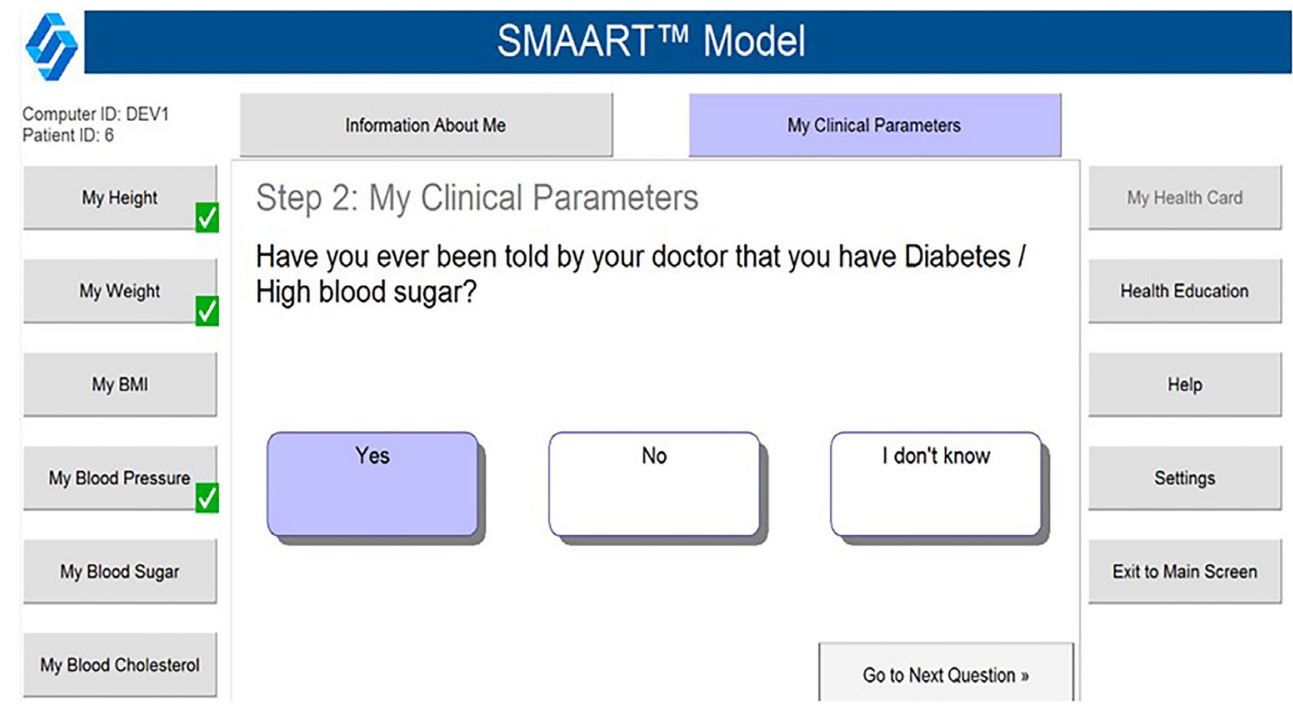

Figure 1 Touch screen, computer-based, and multi-lingual SMAART Informatics platform.

needs of the individual consumer, (IV) timely feedback to the consumer addressing their requirements and $(\mathrm{V})$ regular repetition of the feedback loop of information processing (16). There are various components of SMAART framework informatics that have been outlined in a previous paper $(13,16)$. SMAART PopHI framework provides a platform to collect process and present population health data, in a meaningful and contextually relevant format that is easy to understand.

\section{Swasthya Pahal (bealth for all) using SMAART informatics platform}

Swasthya Pahal (health for all) is an innovative communitybased program, facilitated through an interactive, multilingual, standalone, and internet-enabled touch screen computer-based program that aims to enhance selfmanagement of NCDs including diabetes, hypertension, and obesity among individuals living across diverse community settings. This community program facilitates the collection of individual subjective and objective data using the SMAART informatics platform.

Data gathered on participants included subjective data and objective data. Subjective data comprised responses to a sequence of multiple-choice questions, including (I) location of residence (urban/slum/tribal), (II) sociodemographic variables such as age (years), gender (male/ female), the highest level of education attained (less than high school/some college/graduate and above/none), (III) health behavior variables such as smoking (presently/in the past/never), alcohol consumption (presently/in the past/ never), and physical activity patterns, (IV) clinical status assessments such as ever been told by a doctor about high blood sugar (yes/no/I don't know), and if yes are you currently being treated for your high blood sugar (yes/no/ I don't know), ever been told by a doctor about high blood pressure (yes/no/I don't know), and if yes are you currently being treated for your high blood pressure (yes/no/I don't know). Information related to Knowledge, Attitude, and Practices (KAP) about diabetes and hypertension selfmanagement was also gathered. Objective data was collected using multiple physiological sensors which captured participants' height, weight, blood sugar, and blood pressure levels (Figure 1).

Algorithms ("if and then" rules applied to problemsolving) were applied to the garnered data to generate an electronic evidence-based report called a SMAART health card (Figure 2). The SMAART health card identifies the risk factors of participants across multiple variables and provides tailored recommendations and reinforcement. Public health nutritionists provided individualized lifestyle counselling based on tailored SMAART health cards generated for each individual.

\section{Swasthya Pabal (health for all) follow up}

Individuals were contacted to enroll themselves into mobile-based lifestyle intervention within a month of being 


\section{SMAART TM Model}

\section{My Health Card}

\section{click on any risk factor for more information}

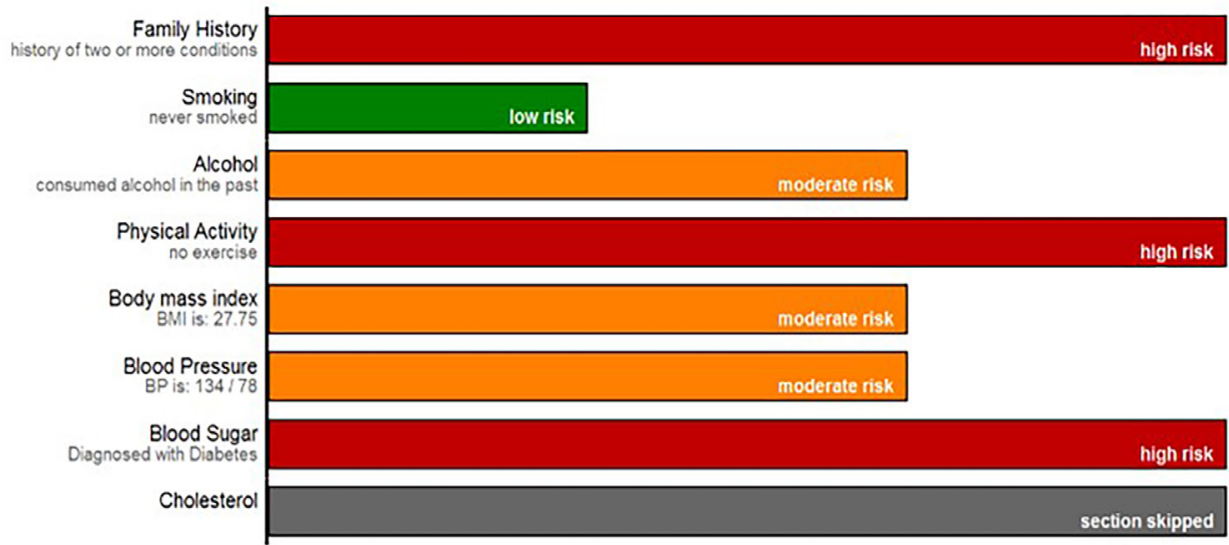

Continue to Education

Figure 2 SMAART health card.

screened during the Swasthya Pahal health camp. During the follow-up call, the lifestyle intervention team gathers feedback about any changes individuals made to their diet, physical activity, and physician referrals. Feedback is also gathered about an individual's interest in receiving lifestyle messages through mobile-based SMS. Information was also gathered on the topic, content type, and frequency of the SMS based health messages (Figure 3).

\section{Methods}

A convenient sample of 64 individuals age 18 years and above present at the Police Sanchar Training Centre, Dehradun in the state of Uttarakhand were enrolled in January 2020. The police personnel had assembled at the Police Sanchar Training Center from all over the State for their usual police training. The Swasthya Pahal pilot program was approved by the Uttarakhand State Police authorities to assess usefulness in screening and helping the individuals to enhance self-management for diabetes, hypertension, and obesity. The Swasthya Pahal program was conducted over two days in January 2020 and individual's health data was recorded using an interactive, bi-lingual (English and Hindi) touch screen, computer-based program.
Self-reported information was gathered using a series of multiple-choice assessments.

\section{Variables measured}

Subjective data was collected and self-reported information was gathered about (I) socio-demographics, (II) health behaviors, (III) clinical status, and (IV) Knowledge, Attitudes, and Practices (KAP).

Objective data assessments included measurements such as height, weight, blood pressure, and blood sugar levels using a series of physiological sensors. A description of these variables is described below.

- Socio-demographics: information gathered comprised age (years), gender (males/female), education attained (less than high school/some college/graduate and above/none).

- Health behaviors: particulars recorded included smoking (presently/in the past/never), alcohol consumption (presently/in the past/ never), use of drugs and body mass index.

- Clinical status: data was gathered on the incidence of blood sugar (ever been told by a doctor about high blood sugar (yes/no/I don't know), blood pressure 


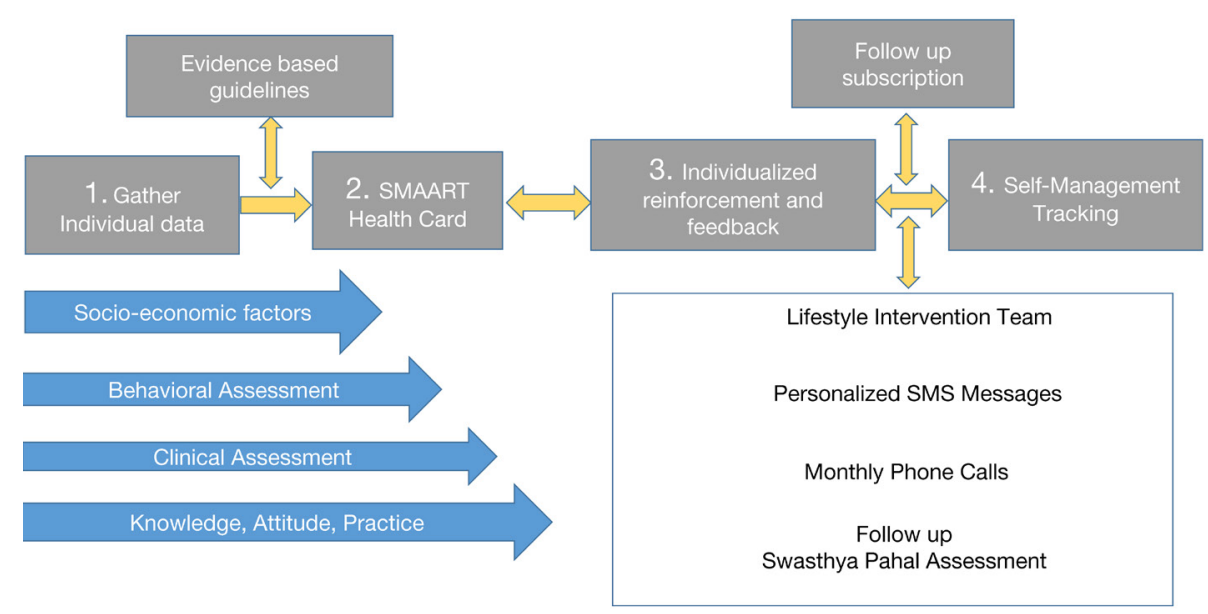

Figure 3 Information flow in Swasthya Pahal (health for all) implementation using SMAART informatics platform.

(ever been told by a doctor about high blood pressure (yes/no/I don't know), blood cholesterol (ever been told by a doctor about high blood cholesterol (yes/ no/I don't know).

- Knowledge, Attitudes, and Practice (KAP): data on the individual's level of understanding about their body mass index, blood pressure, and blood sugar levels were gathered. Information was also gathered whether individuals were currently on treatment for any of the disease risks and the various approaches of treatment that were being utilized (e.g., medicine/ diet/physical activity).

Perceived ease of use (PEOU): the perceived ease of use (PEOU) questionnaire was administered to assess the feasibility of the use of the touch screen computer-enabled Portable Health Information Kiosk to self-manage diabetes, hypertension, obesity, and high cholesterol. PEOU refers to the degree to which using the technology would require a minimum of effort. It characterizes users' perception of the ease of use of the new technology (17). It is a 6-item questionnaire where each of these variables is rated using a 5-point Likert scale, where ' 1 ' depicts 'strongly disagree' and ' 5 ' denotes 'strongly agree'. The questions focused on assessing understandable and clear interaction, Flexible interaction, Easy usage, General easiness, easy learning, and skill enhancement (Table 1).

Additional information gathered at 1 month follow up included any modifications that individuals made in their self-management of diabetes and hypertension, dietary and physical activity, alcohol consumption, and smoking. Information was also gathered related to individuals' perceived interest in receiving SMS based health messages, their content, and frequency. The study was conducted in accordance with the Declaration of Helsinki (as revised in 2013). The study was approved by the Institutional Review Board of the Foundation of Healthcare Technologies Society, New Delhi, India (IRB number: \#FHTS/047/2020). Informed consent was taken from all the study participants.

\section{Statistical analysis}

Descriptive analysis was done to assess mean and standard deviations for the continuous variables and frequency distribution for the categorical variables. Data was analysed using SAS v9.1.

\section{Results}

The mean age of the study participants was $37(\mathrm{SD}=8)$ years. The majority of the respondents were males $(88 \%$; $n=56)$. Majority of the participants had college level education with graduates $(42 \% ; n=27)$ and post-graduates $(41 \%$; $n=26)$. Nearly $44 \%(n=28)$ of them had some family history of diabetes mellitus, hypertension, hypercholesterolemia, or cardiovascular diseases. Hypertension $(31 \% ; n=20)$ was found to be the most common family history among the study participants. Less than half of the study participants were present smokers $(36 \% ; n=23)$ or consumed alcohol $(36 \% ; n=23)$. Sixty-two percent $(n=40)$ of the study participants self-reported doing some of the time to all of the time exercise. Walking $(38 \% ; n=24)$, jogging $(17 \%$; $\mathrm{n}=11)$ and yoga $(9 \% ; \mathrm{n}=6)$ were the most common exercise 
Table 1 Perceived ease of use (PEOU) questionnaire items

\begin{tabular}{ll}
\hline Variables/items & Questions asked \\
\hline $\begin{array}{l}\text { Understandable and clear } \\
\text { interaction }\end{array}$ & $\begin{array}{l}\text { Knowing about health through the use of touch screen computer-enabled portable health information Kiosk } \\
\text { was clear and understandable }\end{array}$ \\
$\begin{array}{l}\text { Flexible interaction } \\
\text { Did you find the touch screen computer-enabled portable health information Kiosk easy to navigate from one } \\
\text { screen to another screen? }\end{array}$ \\
$\begin{array}{l}\text { Did you find touch screen computer-enabled portable health information Kiosk to be easy to use } \\
\text { General easiness }\end{array}$ \\
$\begin{array}{l}\text { Overall, did you find the touch screen computer-enabled portable health information Kiosk easy } \\
\text { Was it easy to learn about your health through the touch screen computer-enabled portable health information } \\
\text { Kkill enhancement }\end{array}$ \\
$\begin{array}{l}\text { Did you find that your knowledge/skill has enhanced through the use of touch screen computer-enabled } \\
\text { portable health information Kiosk to maintain a better health/lifestyle }\end{array}$ \\
\hline
\end{tabular}

types as self-reported by the individuals (Table 2).

\section{Clinical assessment}

Only one individual self-reported having type 2 diabetes and was presently on treatment to manage it. Hypertension was self-reported among $13 \%(n=8)$ of the individuals, however, $87 \%(n=7)$ of them were not on any treatment for hypertension. A hundred percent of those with high blood cholesterol were on treatment (Table 3).

\section{Characterization of individuals into various obesity, diabetic and hypertensive categories}

Findings of our objective assessments showed that the average weight of the individuals was $76 \mathrm{~kg}(\mathrm{SD}=10)$, body mass index was $27(\mathrm{SD}=3$ ), random blood sugar was 143 (SD $=71)$, systolic blood pressure was $140(\mathrm{SD}=17)$, diastolic blood pressure was $87(\mathrm{SD}=11)$ and pulse was $81(\mathrm{SD}=13)$. Individuals were categorized as hypertensive, overweight or obese, or diabetic based on the series of objective measurements of their blood pressure, weight, and blood sugar levels.

When JNC 8 criteria (18) was implemented on recorded blood pressure measurements, $63 \%(n=40)$ of the individuals had normal blood pressure, $8 \%(\mathrm{n}=5)$ were prehypertensive, $19 \%(\mathrm{n}=12)$ in stage 1 and $10 \%(\mathrm{n}=7)$ in stage 2 hypertension (Table 4). Of the individuals with normal blood pressure levels, only $10 \%$ of them characterized themselves correctly as having normal blood pressure while the majority of them characterized themselves either as prehypertensive or stage 1 hypertensive (Table 4). More than half of the individuals were not able to classify themselves correctly to which category of the stage of blood pressure they belonged reflecting poor knowledge of hypertension among them. Similarly, limited knowledge of body mass index and blood pressure sugar levels was observed.

\section{Perceived ease of use}

Results of perceived ease of use of a touch screen, computerbased, SMAART interactive platform showed that more than half of the individuals agreed to strongly agree that the system was understandable (98\%; $n=62)$. More than half of them found the system to be flexible, easy usage, general easiness, easy learning, and skill enhancement (Figure 4).

\section{Follow-up assessment}

Individuals screened during the health camp were then followed-up by the lifestyle team after a month to determine if individuals had made any lifestyle modifications based on the feedback they received from Swasthya Pahal (health for all) initiative delivered using an interactive SMAART informatics self-management platform. Ninety-one percent $(n=58)$ of the individuals responded to the phone call while the remaining participants could not be contacted due to geographic network issues. Of the individuals who attended the call, more than half of them indicated making little changes to their diet (68\%), exercise (64\%), smoking (67\%), and alcohol consumption (57\%) to enhance their selfmanagement. Results showed that $29 \%$ of the individuals self-reported making complete modifications to their smoking and alcohol consumption $27 \%$ after they were 
Table 2 Descriptive analysis of the study participants

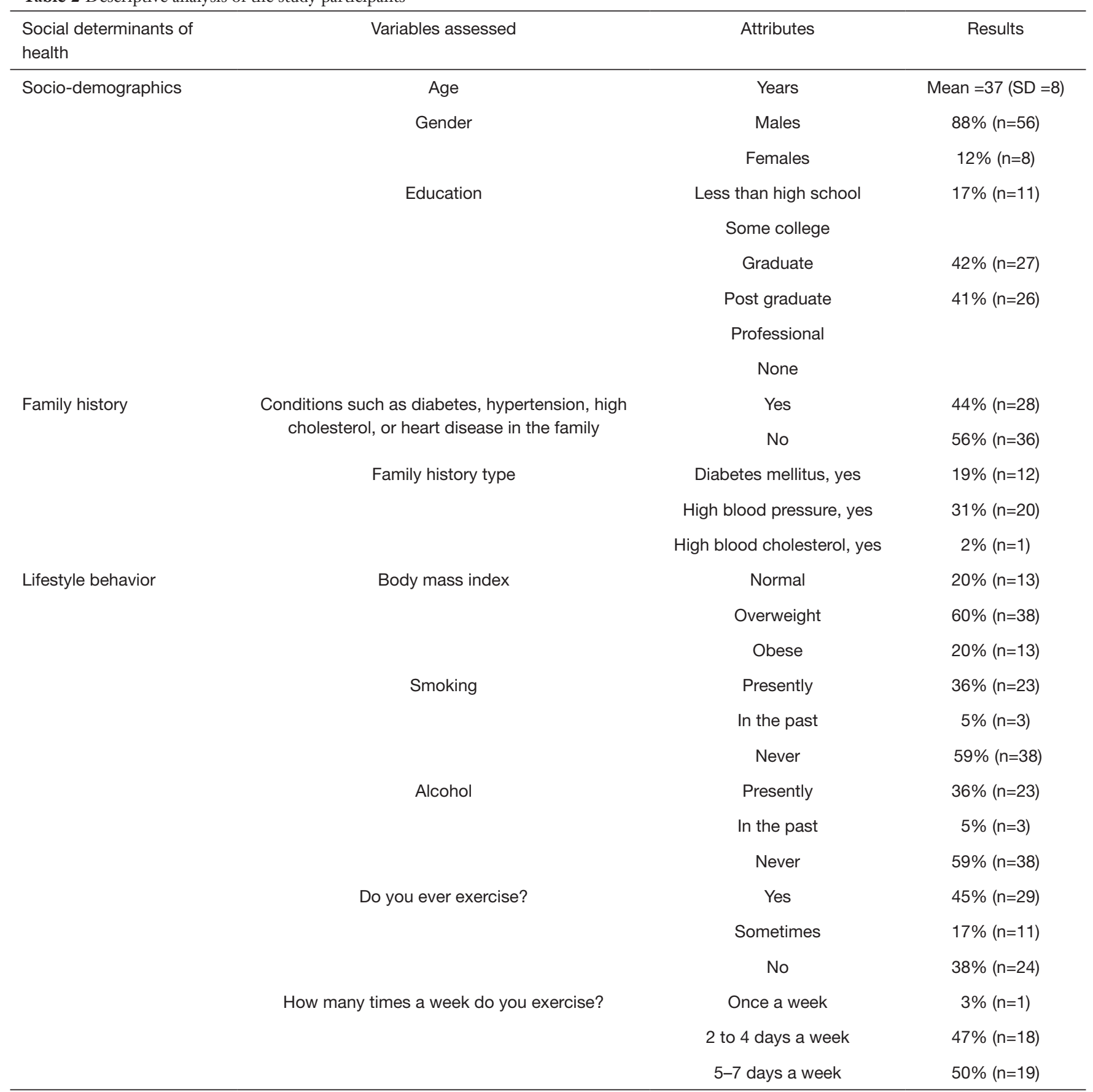

screened during the Swasthya Pahal (health for all) program (Figure 5). More than half of the participants were not doing any self-monitoring of hypertension, or obesity at home $(71 \% ; n=41)$. However, $17 \%(n=10)$ were doing some form of self-monitoring in their home setting. Thirty-one percent of the participants had done physician referral while
$21 \%$ of them had planned to do it in the future. However, $31 \%$ of them did not plan to make any physician referral.

\section{Individual perception about SMS bealth messages}

Data was also collected on participants perception about 
Table 3 Percentage distribution of study participants for clinical assessment

\begin{tabular}{|c|c|c|c|}
\hline Clinical variables assessment & Yes & No & I don't know \\
\hline Treated & $100 \%(n=1)$ & & \\
\hline \multicolumn{4}{|l|}{ Not treated } \\
\hline Ever been told by your doctor that you have hypertension/high blood pressure? & $13 \%(n=8)$ & $84 \%(n=54)$ & $3 \%(n=2)$ \\
\hline Not treated & $87 \%(n=7)$ & & \\
\hline $\begin{array}{l}\text { Ever been told by your doctor that you have hypercholesterolemia/high blood } \\
\text { cholesterol? }\end{array}$ & $5 \%(n=3)$ & $92 \%(n=59)$ & $3 \%(n=2)$ \\
\hline Treated & $100 \%(n=3)$ & & \\
\hline
\end{tabular}

Table 4 Self-perceived knowledge about individuals' blood pressure, weight, and blood sugar measurements

\begin{tabular}{|c|c|c|c|c|c|}
\hline Clinical variable assessment & \multicolumn{5}{|c|}{ Individuals knowledge levels } \\
\hline \multicolumn{6}{|l|}{ Recorded blood pressure levels } \\
\hline Normal $(n=40)(<120 / 80 \mathrm{mmHg})$ & $10 \%(n=4)$ & $55 \%(n=22)$ & $33 \%(n=13)$ & $2 \%(n=1)$ & \\
\hline $\begin{array}{l}\text { Prehypertension }(n=5) \\
(120-139 \text { or } 80-89 \mathrm{mmHg})\end{array}$ & & $80 \%(n=4)$ & $20 \%(n=1)$ & & \\
\hline $\begin{array}{l}\text { Stage } 2 \text { hypertension }(n=7) \\
(\geq 160 / 100 \mathrm{mmHg})\end{array}$ & $14 \%(n=1)$ & $58 \%(n=4)$ & $14 \%(n=1)$ & $14 \%(n=1)$ & \\
\hline Body mass index levels & Underweight & Normal & Overweight & Obese & I don't know \\
\hline Obese $(n=13)(\geq 30)$ & & & $39 \%(n=5)$ & $46 \%(n=6)$ & $15 \%(n=2)$ \\
\hline Blood sugar levels & & Normal & Abnormal & I don't know & \\
\hline$<140(\mathrm{n}=48)$ & & $79 \%(n=38)$ & & $21 \%(n=10)$ & \\
\hline $140-199(n=6)$ & & $50 \%(n=3)$ & & $50 \%(n=3)$ & \\
\hline$\geq 200(n=10)$ & & $30 \%(n=3)$ & $20 \%(n=2)$ & $50 \%(n=5)$ & \\
\hline
\end{tabular}

receiving SMS based health messages. Eight-six percent $(\mathrm{n}=50)$ of the individuals preferred receiving SMS based health messages. While the remaining expressed difficulty in receiving the messages because of cellular network barriers. Thirty-six percent $(\mathrm{n}=18 / 50)$ of the individuals preferred to receive daily SMS messages while more than half of them $(64 \% ; n=32)$ preferred weekly messages
(Figure 6).

Health topics preferred have been outlined in Figure 7. The majority of individuals preferred to receive messages related to hypertension and obesity. Lifestyle messages related to diet and physical activity were perceived to be more useful followed by messages related to sleep modification, smoking, and alcohol consumption. 


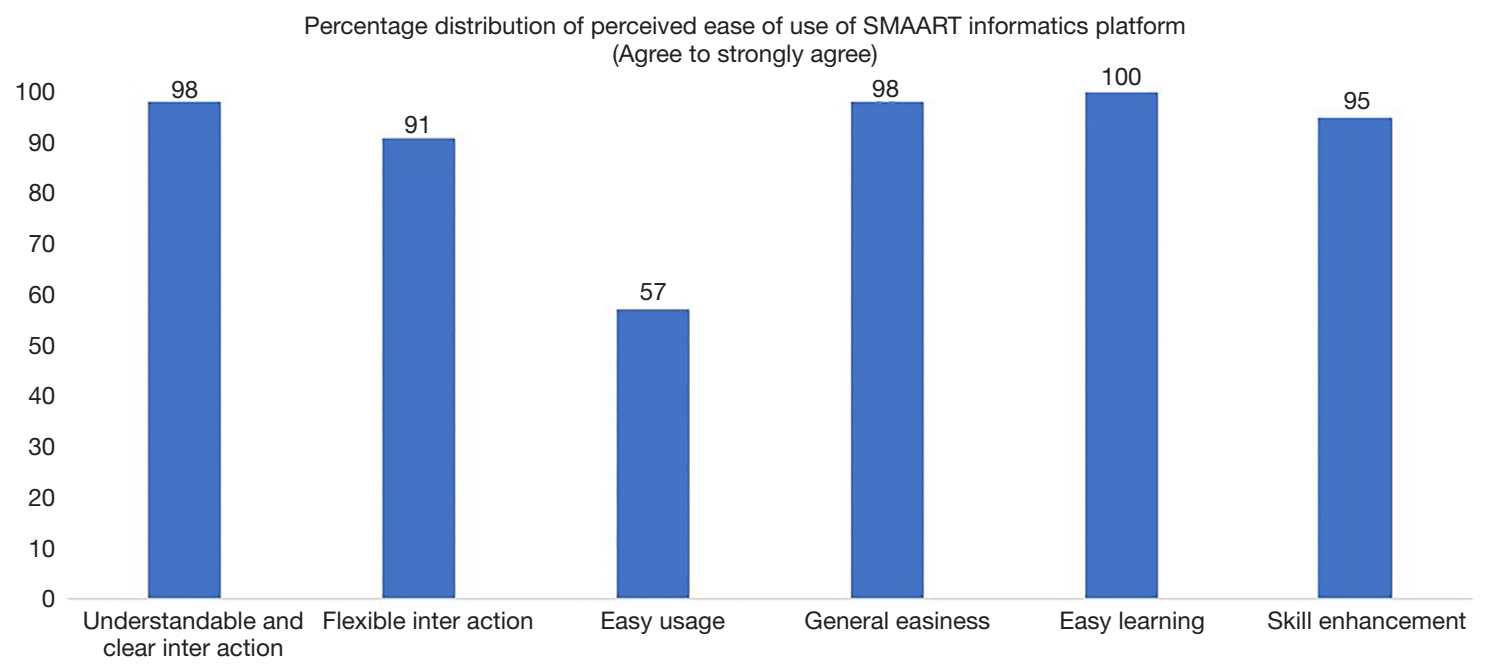

Figure 4 Percentage distribution of perceived ease of use of SMAART informatics platform.

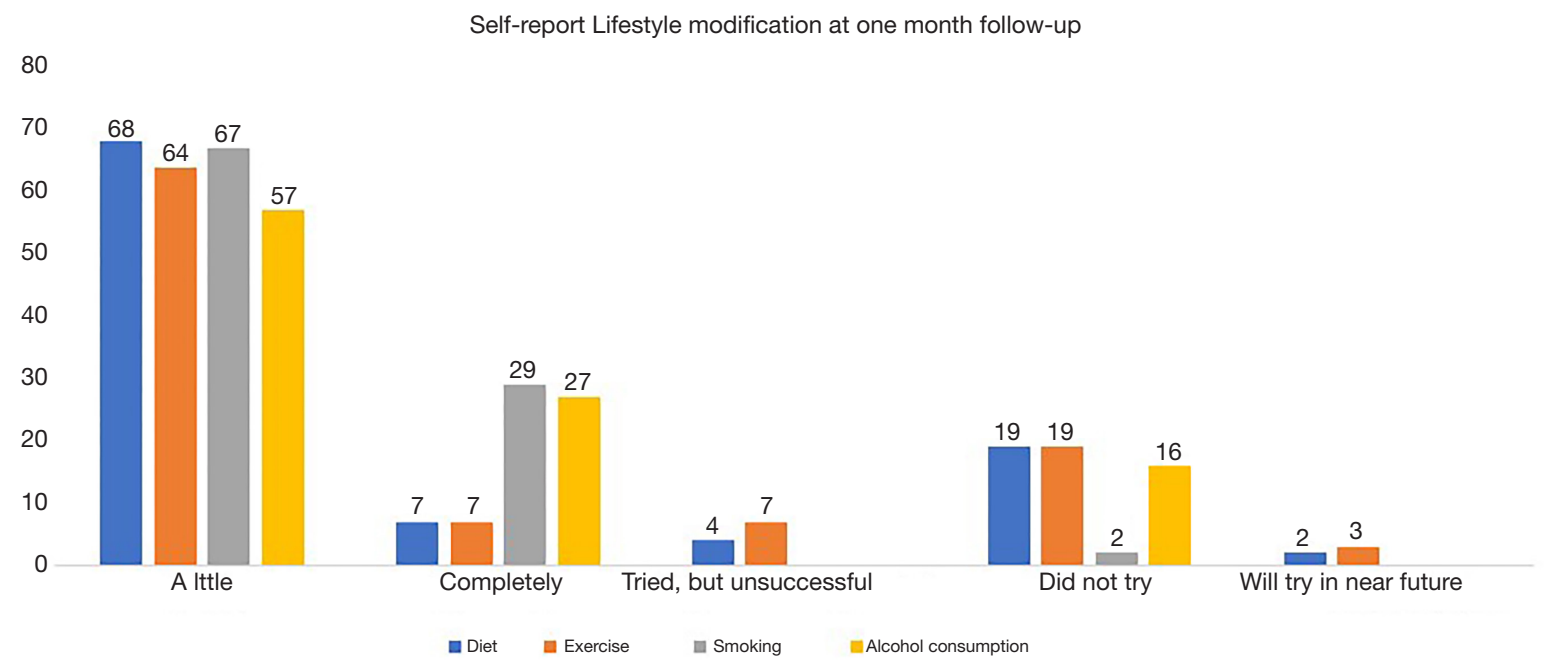

Figure 5 Percentage distribution of self-report lifestyle modification at 1 month follow up.

\section{Discussion}

NCDs are the leading cause of mortality, accounting for nearly $63 \%$ of global deaths (36 million people). Majority of the deaths related to NCDs (80\%) occur in low and middleincome countries (19).

Considering the population health and associated challenges like resource-constrained healthcare systems and poor living conditions, it is imperative to research potential approaches to improve the over-burden of NCDs in India. Moreover, large population size can be a barrier in providing conventional care for NCDs patients as they need constant monitoring and treatment (5). Critical challenges such as access, dearth of transportation services to healthcare facilities, inadequate knowledge about health services, and unaffordable healthcare can affect well-timed prognosis and cure of NCDs (20). These barriers entail implementation of interventions for making medicalcare easily available, accessible, and acceptable to the patients with chronic illness and NCDs.

The present study describes SMAART, a PopHI framework that provides a platform to collect process and present population health data, in a purposeful and contextually pertinent format that is easy to understand. 


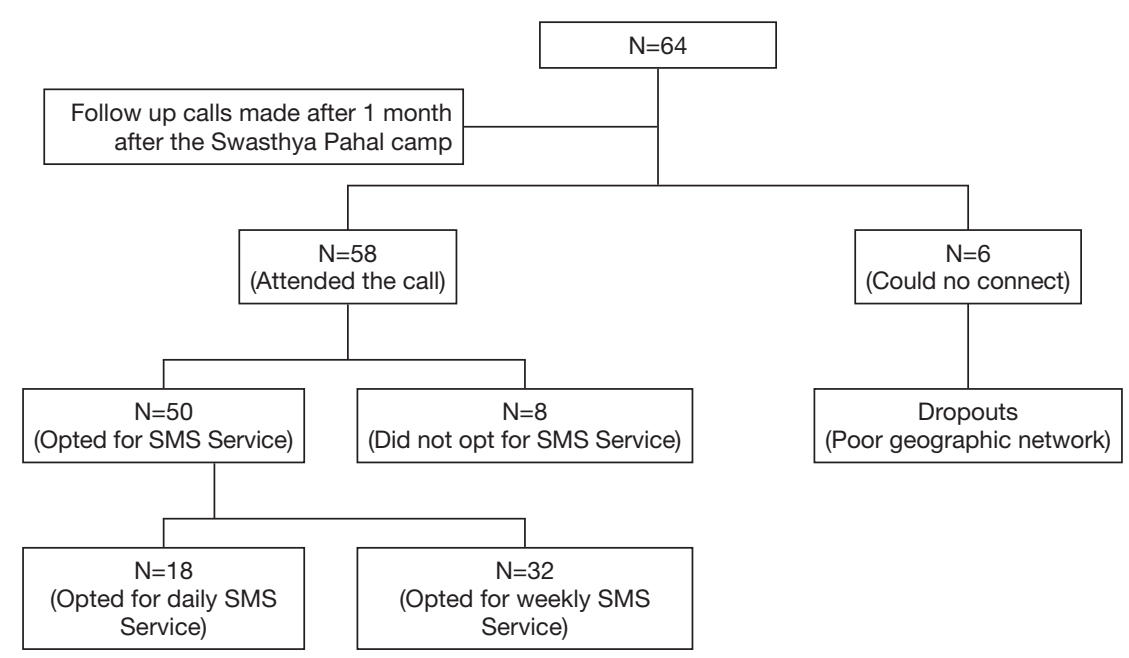

Figure 6 Individuals' perception of SMS enabled health messages.

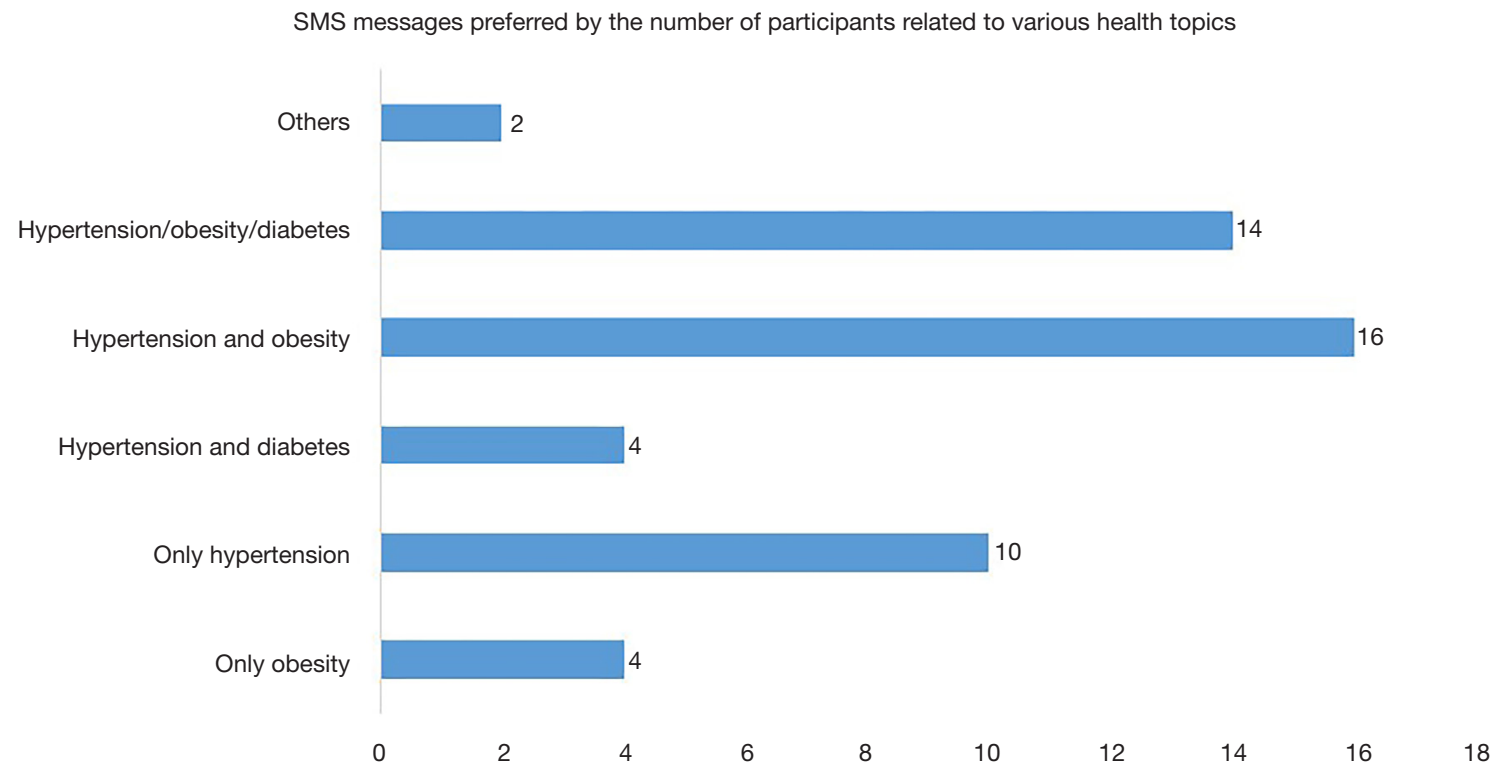

Figure 7 SMS based messages preferred for various health topics.

We describe the implementation of Swasthya Pahal (health for all), a community based, interactive, self-management program that utilizes the SMAART informatics framework to collect data on distinct variables such as sociodemographic, clinical, and health behavior, to generate tailored risk profile in the form of a SMAART card. It provides individualized self-management plan of action supported by perpetual monitoring and interactive health information and shared decision-making.

Results of our study demonstrate a high burden of obesity and hypertension among police personnel that were screened during the Swasthya Pahal health camp. Findings are similar to other previous studies that have reported law enforcement officers to have a prevalence of high BMI and associated diseases such as high blood pressure, hyperlipidaemia, cardiovascular diseases along with tobacco usage and physical inactivity (21). Additionally, epidemiological studies have reported a higher prevalence of obesity among police personnel, in comparison to the non-police workforce (22). 
An extensive range of digital and technological interventions have emerged to provide an extensive array of healthcare services to individuals living with various chronic conditions. Various modalities of digital interventions in healthcare include devices and platforms, such as mobile phones, websites, software, wearable devices, and tablet computers, using online and offline digital technology platforms; these are collectively termed as digital health. The WHO acknowledges the potential of digital health interventions to accomplish universal health coverage and ensure high-quality care to individuals.

Results of our study have shown that an interactive, touch screen, bi-lingual, SMAART informatics platform was perceived easy to use by the police personnel to self-manage their diabetes, hypertension, and obesity. Digital health interventions lead to better symptom evaluation, selfcaremanagement, lessening of symptom distress, and knowledge about health conditions, patient-provider interaction, well-timed care-seeking, follow-up and referral, treatment adherence, and enhanced quality of well-being among the patients living with NCDs (4). The implementation of such advanced digital and technological interventions is comparatively less among the low and middle-income countries. Although, in the Indian context, the use of digital technologies is gathering momentum in recent years (23). However, most digital innovations are being implemented within the hospital settings, where healthcare workers have access to them.

There are several strengths to this study. First, we have demonstrated the feasibility of a digital health intervention that aims to address self-management of NCDs among police personnel in a community setting. Second, the SMAART informatics platform incorporated a multifaceted approach to record data on variables such as sociodemographics, medical assessment, health behavior, and KAP to generate an individualized risk profile and followed by tailored lifestyle counseling to help them self-manage their condition. Third, the user feedback has been gathered on the perceived use of the SMAART informatics platform, preference for receiving SMS based health messages or not, and the message frequency and health topics preferred. Fourth, individuals were motivated to modify their lifestyle behavior even with limited interaction during the Swasthya Pahal (health for all) health camp. However, there are several limitations to the study. First, the study is crosssectional, has a small sample size, and needs to evaluate the long-term impact of the Swasthya Pahal program in the self-management of NCDs.
Our study showed that the Swasthya program implemented using the SMAART informatics framework can be utilized to screen obesity, diabetes, and hypertension among police personnel for improved disease prevention, monitoring, and self-management of NCDs.

\section{Acknowledgments}

The authors are grateful to the all the police personnel who participated in the study and the Uttarakhand State Police who gave permission to carry out this study. The authors thank all policemen who participated in the study without whom the study would not have been possible.

Funding: None.

\section{Footnote}

Reporting Checklist: The authors have completed the MDAR reporting checklist. Available at http://dx.doi.org/10.21037/ mhealth-20-110

Data Sharing Statement: Available at http://dx.doi. org/10.21037/mhealth-20-110

Conflicts of Interest: All authors have completed the ICMJE uniform disclosure form (available at http://dx.doi. org/10.21037/mhealth-20-110). AJ serves as an unpaid editorial board member of mHealth from December 2019 to November 2021. The other authors have no conflicts of interest to declare.

Ethical Statement: The authors are accountable for all aspects of the work in ensuring that questions related to the accuracy or integrity of any part of the work are appropriately investigated and resolved. The study was conducted in accordance with the Declaration of Helsinki (as revised in 2013). The study was approved by Institutional Review Board of the Foundation of Healthcare Technologies Society, New Delhi, India (IRB number: \#FHTS/047/2020). Informed consent was taken from all the study participants.

Open Access Statement: This is an Open Access article distributed in accordance with the Creative Commons Attribution-NonCommercial-NoDerivs 4.0 International License (CC BY-NC-ND 4.0), which permits the noncommercial replication and distribution of the article with the strict proviso that no changes or edits are made and the 
original work is properly cited (including links to both the formal publication through the relevant DOI and the license). See: https://creativecommons.org/licenses/by-nc-nd/4.0/.

\section{References}

1. GBD 2015 Risk Factors Collaborators. Global, regional, and national comparative risk assessment of 79 behavioural, environmental and occupational, and metabolic risks or clusters of risks, 1990-2015: a systematic analysis for the Global Burden of Disease Study 2015. Lancet 2016;388:1659-724. Erratum in: Lancet 2017;389:e1.

2. World Health Organization. Global action plan for the prevention and control of noncommunicable diseases 2013-2020. World Health Organ 2013. Report No. 9241506237.

3. Geldsetzer P, Manne-Goehler J, Theilmann M, et al. Diabetes and hypertension in India: a nationally representative study of 1.3 million adults. JAMA Intern Med 2018;178:363-72.

4. Hossain MM, Tasnim S, Sharma R, et al. Digital interventions for people living with non-communicable diseases in India: a systematic review of intervention studies and recommendations for future research and development. Digit Health 2019;5:2055207619896153.

5. Nethan S, Sinha D, Mehrotra R. Non communicable disease risk factors and their trends in India. Asian Pac J Cancer Prev 2017;18:2005-10.

6. Ravikumar TS, Kanagarethinam R, Nair D, et al. Are Police Personnel in Puducherry Healthy? Findings from "Partners in Prevention" Programme in Puducherry, India. Indian J Occup Environ Med 2017;21:84-8.

7. Parkash J, Kalhan M, Singhania K, et al. Prevalence of hypertension and its determinants among policemen in a City of Haryana, India. Int J Appl Basic Med Res 2019;9:143-7.

8. Meena JK, Rustagi N, Jangir V. 204 A non-communicable diseases and risk factors among police personnel in Jodhpur, India. Occup Environ Med 2018;75:abstr A144.

9. Anshel MH. A conceptual model and implications for coping with stressful events in police work. Crim Justice Behav 2000;27:375-400.

10. World Health Organization. WHO releases first guideline on digital health interventions. 2019. [cited on 30th January 2020]. Available online: https://www.who.int/ news/item/17-04-2019-who-releases-first-guideline-ondigital-health-interventions

11. Zelenika I, Pearce JM. The Internet and other ICTs as tools and catalysts for sustainable development: innovation for 21st century. Inform Dev 2013;29:217-32.

12. Lewis T, Synowiec C, Lagomarsino G, et al. E-health in low-and middle-income countries: findings from the Center for Health Market Innovations. Bull World Health Organ 2012;90:332-40.

13. Joshi A, Perin DMP, Arora M. Using Portable Health Information Kiosk to assess chronic disease burden in remote settings. Rural Remote Health 2013;13:2279.

14. Howitt P, Darzi A, Yang G-Z, et al. Technologies for global health. Lancet 2012;380:507-35.

15. Williams DR, Costa MV, Odunlami AO, et al. Moving upstream: how interventions that address the social determinants of health can improve health and reduce disparities. J Public Health Manag Pract 2008;14:S8-17.

16. Joshi A, Arora M, Malhotra B. Usability evaluation of a portable health information kiosk using a SMAARTTM intervention framework. Glob J Health Sci 2017;9:153-68.

17. Davis FD. Perceived usefulness, perceived ease of use, and user acceptance of information technology. Manag Inf Syst Q 1989;13:319-40.

18. Page MR. The JNC 8 hypertension guidelines: an indepth guide. Am J Manag Care 2014;20:E8.

19. World Health Organization. Deaths from NCDs. WHO [Internet] [Cited on 4th April]. Available online: https:// www.who.int/gho/ncd/mortality_morbidity/ncd_total_ text/en/

20. Balarajan Y, Selvaraj S, Subramanian S. Health care and equity in India. Lancet 2011;377:505-15.

21. Birnbaum HG, Mattson ME, Kashima S, et al. Prevalence rates and costs of metabolic syndrome and associated risk factors using employees' integrated laboratory data and health care claims. J Occup Environ Med 2011;53:27-33.

22. Plat MJ, Frings-Dresen MH, Sluiter JK. A systematic review of job-specific workers' health surveillance activities for fire-fighting, ambulance, police and military personnel. Int Arch Occup Environ Health 2011;84:839-57.

23. Orton M, Agarwal S, Muhoza P, et al. Strengthening delivery of health services using digital devices. Glob Health Sci Pract 2018;6:S61-71.

doi: $10.21037 /$ mhealth-20-110

Cite this article as: Joshi A, Kaur M, Arora S, Bhatt A, Sharma P, Kaur H, Kumar K, Arora M, Malhotra B Anshuman A. A pilot evaluation of Swasthya Pahal program using SMAART informatics framework to support NCD selfmanagement. mHealth 2021;7:55. 